\section{Discussion}

We have shown that picking up fasciculation spikes from denervated muscle on the ECG is not a rare event. The fasciculations that can be so recorded do not have to be very large in amplitude or particularly close to the surface electrodes. Perhaps the spikes have not been emphasised before because their significance has not been recognised and therefore they have been overlooked or simply discounted.

When an ECG shows these spikes it should prompt a search for underlying neuromuscular disease, if this is not already appreciated, and attention should be drawn to them in the ECG report. It should be possible to say from which limb the dis- turbance has come by seeing in which leads the artefact occurs. The significance of these spikes should be appreciated by all those who read and record ECGs, especially the latter because by too generous a use of the filter they may be missed.

Requests for reprints should be addressed to Dr D J Thomas, The National Hospital, Queen Square, London WC1N 3BG.

\section{References}

1 Williams, D O, and Thomas, D J, British Heart fournal, in press.

${ }^{2}$ Harper, R, et al, British Heart fournal, 1974, 36, 610.

\title{
Failure of phenobarbitone to prevent febrile convulsions
}

\author{
J Z HECKMATT, A B HOUSTON, D J CLOW, J B P STEPHENSON, K L DODD, \\ G T LEALMAN, R W LOGAN
}

British Medical fournal, 1976, 1, 559-561

\section{Summary}

One-hundred-and-sixty-five children without known neurological disorder who presented with their first febrile convulsion between the ages of six months and three years were assigned to daily phenobarbitone treatment or to a control group and followed up at a special clinic for six months. One-hundred-and-sixty-one children completed the trial, and of the 88 children assigned to phenobarbitone treatment 10 had further convulsions during this period compared with 14 of the 73 control children. Only 49 of those assigned to phenobarbitone took the drug regularly throughout the trial, and four of these had further febrile convulsions, a proportion not significantly different from that in the controls. All four had mean plasma phenobarbitone concentrations over $69 \mu \mathrm{mol} / 1(16 \mu \mathrm{g} / \mathrm{ml})$ during the trial and in three the plasma concentration was at or over this figure within eight hours of the repeat convulsion. Regular phenobarbitone does not seem to prevent febrile convulsions. Attention should instead be directed to organising emergency services to allow early termination of febrile convulsions, whether first or subsequent, to prevent irreversible brain damage.

\section{Introduction}

There is now considerable evidence that febrile convulsions if prolonged and severe may cause irreversible cerebral injury,

Royal Hospital for Sick Children, Yorkhill, Glasgow

J Z HECKMATT, MB, MRCP, medical registrar

A B HOUSTON, MB, MRCP, senior medical registrar

D J CLOW, MRCP, $\mathrm{DCH}$, senior medical registrar (now consultant paediatrician, Dumfries and Galloway Royal Infirmary, Dumfries)

J B P STEPHENSON, MRCP, DCH, consultant in paediatric neurology

Departments of Child Health and Biochemistry, University of Glasgow, Glasgow

K L DODD, MRCP, DCH, senior registrar

G T LEALMAN, MRCP, DCH, registrar (now senior registrar, Bradford Children's Hospital, Bradford)

$R$ W LOGAN, MRCPATH, MRCP GLAS, consultant in biochemistry

leading to mental handicap, cerebral palsy, or secondary epilepsy, including that arising from mesial temporal sclerosis. ${ }^{1-6}$ There is also evidence that the convulsions that induce this brain damage differ from more common benign febrile convulsions only in their duration. ${ }^{2}{ }^{4}{ }^{5}$ Since the liability to prolonged convulsions increases with each recurrence ${ }^{1}$ a treatment that prevented recurrence of convulsions would diminish the number of people handicapped as a result of severe attacks. Much enthusiasm therefore greeted the publication of a controlled trial by Faerø et al, ${ }^{7}$ who claimed that phenobarbitone would prevent febrile convulsions if the plasma concentration was maintained at the high level of $69 \mu \mathrm{mol} / \mathrm{l}(16 \mu \mathrm{g} / \mathrm{ml})$ or over. As their trial included only a few patients and because of the importance of the conclusion for preventive paediatrics we repeated the study on a larger sample.

\section{Patients and methods}

Febrile convulsions were defined for the purpose of this study as convulsions occurring with fever due to infections other than those primarily affecting the brain. ${ }^{8}$ The incidence of repeat convulsions within six months of a first convulsion was determined in two groups of children aged six months to three years who presented at the Royal Hospital for Sick Children, Glasgow, from September 1973 to September 1974. The nature and purpose of this trial was explained to the parents, whose permission was essential to their child's inclusion in this study. In addition to those with central nervous system (CNS) infections, children were excluded if there was a history of previous convulsion or evidence from the history or examination of pre-existing CNS abnormality.

Acute medical care in the Royal Hospital for Sick Children is shared equally between two medical paediatric units. Children suitable for the trial attending the hospital were allocated into a treatment or control group according to which unit was "receiving" at the time of the convulsion. Thus children having a convulsion in the 24 hours starting at 9 am on Mondays, Wednesdays, Fridays, and alternate Sundays became controls and received no treatment while prophylactic phenobarbitone was given to those who presented on the other days.

There were no differences between the two medical units in the management of the presenting convulsion. Those children who were convulsing on admission to hospital were treated successfully with intravenous diazepam. High fever was reduced by tepid sponging. Children admitted into the treatment group were prescribed phenobarbitone $4-5 \mathrm{mg} \mathrm{kg}^{-1}$ day $^{-1}$ in divided doses. They were seen in a special clinic after enrolment in the trial and then every one to three months for six months. At each attendance venous blood was taken for phenobarbitone estimation and the dose adjusted if necessary to 
maintain the plasma level between 65 and $129 \mu \mathrm{mol} / 1$ ( 15 and 30 $\mu \mathrm{g} / \mathrm{ml}$ ). At the same clinic controls were similarly followed up but no blood samples were taken from them.

All parents were given general advice on measures to reduce any subsequent fevers. They were asked to attend the hospital within 24 hours of a further convulsion and in all such children receiving phenobarbitone the plasma level was then estimated. When children defaulted from the follow-up clinic information about them was obtained by our specialist health visitor, and the one child whose parents reported a further convulsion was seen at the hospital.

Phenobarbitone was estimated on $1 \mathrm{ml}$ of plasma by gas-liquid chromatography using a temperature-programmed modification of the method of MacGee. ${ }^{9}$ During the three years in which our laboratory has participated in a United Kingdom quality control scheme for antiepileptic drug determination this method has given consistently accurate results.

\section{Results}

A total of 165 patients were admitted into the trial-90 into the treatment and 75 into the control group. Two patients in each group were completely lost to follow-up, making the final numbers 88 and 73 respectively. Thirty-nine of the 88 children stopped taking phenobarbitone for a variety of reasons, leaving only $49(56 \%)$ who completed treatment. The age distribution in each group was similar and there were only slight variations in family history, sex distribution, and incidence of a severe initial convulsion (see table).

During the six months' follow-up there were 24 repeat convulsions. Fourteen $(19 \%)$ occurred in the control group of 73 and $10(11 \%)$ among the 88 children started on treatment. Four were in the group of $49(8 \%)$ children who completed treatment.

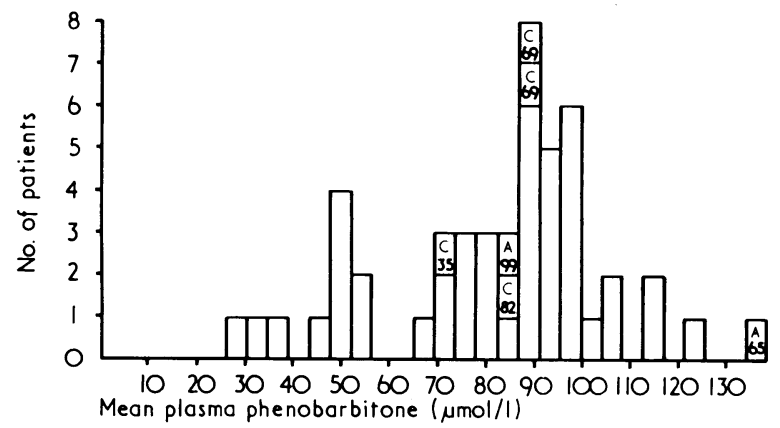

Mean plasma phenobarbitone concentrations in patients who took phenobarbitone continuously for six months. $\mathrm{C}=$ Febrile convulsion while on treatment. $A=$ Febrile "absence" while on treatment. Numbers shown indicate phenobarbitone concentration within 12 hours of the event.

Conversion: SI to traditional units-Phenobarbitone: $1 \mu \mathrm{mol} / 1 \approx 0.23$ $\mu \mathrm{g} / \mathrm{ml}$.

The figure shows that the mean plasma phenobarbitone levels over the six months in the 49 patients on regular treatment was above $65 \mu \mathrm{mol} / 1(15 \mu \mathrm{g} / \mathrm{ml})$ in $39(82 \%)$. The four who had a repeat convulsion had mean plasma levels above $65 \mu \mathrm{mol} / \mathrm{l}$, and in three of them the level recorded within eight hours of the repeat fit was above this, being $69 \mu \mathrm{mol} / 1(16 \mu \mathrm{g} / \mathrm{ml})$ in two and $82 \mu \mathrm{mol} / \mathrm{l}(19 \mu \mathrm{g} / \mathrm{ml})$ in one. The fourth child had a level of $35 \mu \mathrm{mol} / 1(8 \mu \mathrm{g} / \mathrm{ml})$ at the time, but the level was $73 \mu \mathrm{mol} / 1(17 \mu \mathrm{g} / \mathrm{ml})$ four weeks before and $95 \mu \mathrm{mol} / 1$ $(22 \mu \mathrm{g} / \mathrm{ml})$ four weeks after, with no change in the prescribed dose. The difference in the incidence of a repeat convulsion when comparing four patients out of the 49 who took phenobarbitone regularly with 14 out of 73 controls did not reach statistical significance $\left(\chi^{2}=2.83 ; \mathrm{DF}=1 ; 0 \cdot 10>\mathrm{P}>0.05\right)$

During a febrile episode two further patients, both on phenobarbitone, had a period in which they stared and were uncommunicable without any convulsive movements. We called these two episodes "febrile absences"; the blood levels of phenobarbitone are shown in the figure $(65$ and $99 \mu \mathrm{mol} / 1$ ( 15 and $23 \mu \mathrm{g} / \mathrm{ml})$ ). One patient who discontinued phenobarbitone and two controls became "jittery" when feverish. One patient in the treatment group had an unprovoked convulsion after he had taken only one dose of phenobarbitone and although his mean level over the six months was $86 \mu \mathrm{mol} / \mathrm{l}(20 \mu \mathrm{g} / \mathrm{ml})$ he was not included among the four patients with repeat convulsions in the adequately treated group.

Thirty-nine children stopped taking phenobarbitone for a variety of reasons. It had to be discontinued in 16 of these because of behaviour problems (overactivity, unpleasant behaviour, temper tantrums, and not sleeping at night), with improvement in 12 . Four of these 16 had a repeat convulsion. In the remaining 23 patients phenobarbitone was discontinued because the parents disliked venepuncture (one case), the child would not swallow tablets (one), the family doctor thought phenobarbitone was unnecessary (two), the child was drowsy or unsteady (four), or the parents stopped or only intermittently gave phenobarbitone for miscellaneous reasons (15). Only one of these 23 patients had a further fit. Five of the 49 patients who took phenobarbitone regularly had behaviour difficulties (which later subsided with a reduction in dose or when the drug was stopped after the trial), and three control children had similar problems.

Nineteen children (seven controls and 11 treated children) suffered a severe initial convulsion; this was defined as a convulsion lasting longer than 30 minutes or followed by a post-convulsive hemiparesis. Only five of the 11 children on phenobarbitone took the drug regularly during the trial.

\section{Discussion}

Our results have shown, in contrast to those of Faerø et al,? that apparently adequate anticonvulsant treatment did not prevent further convulsions, and although the rate of recurrence was lower in those taking phenobarbitone than in controls, the difference was not significant. Like Faerø et $a l^{7}$ we chose a trial period of six months to avoid matching treated and control patients exactly for age, sex, and family history of febrile convulsion. These factors influence the recurrence rate beyond six months' follow-up but evidently not within this time. ${ }^{10}$

It could be argued that had our sample been even larger a statistically significant difference might have emerged between the recurrence rate in children treated with phenobarbitone and controls. Nevertheless, all four recurrences among children who took phenobarbitone regularly were in those with mean plasma concentrations over the critical value of $69 \mu \mathrm{mol} / 1(16 \mu \mathrm{g} / \mathrm{ml})$. Moreover, the plasma phenobarbitone concentration within eight hours of the recurrent convulsion was at this level or higher in three of these four children. This is identical evidence to that obtained by Melchior et al ${ }^{11}$ in a controlled trial of phenytoin in children under the age of three who suffered convulsions, which was accepted as "decisive proof" that phenytoin could not prevent febrile convulsions under these circumstances. ${ }^{1}$

Comparison between 49 children continuously treated with phenobarbitone for six months and 73 control children

\begin{tabular}{|c|c|c|c|c|c|c|c|c|c|c|c|c|}
\hline & & & & & & \multirow[t]{2}{*}{$\begin{array}{c}\text { No of } \\
\text { patients }\end{array}$} & \multirow[t]{2}{*}{$\underset{\text { age (months) }}{\operatorname{Mean}( \pm 1 \text { SD) }}$} & \multirow[t]{2}{*}{$\begin{array}{l}\text { No of children } \\
\text { under } 14 \text { months }\end{array}$} & \multicolumn{2}{|c|}{$\begin{array}{l}\text { No with history of convulsions } \\
\text { in first degree relatives }\end{array}$} & \multirow[t]{2}{*}{$\begin{array}{l}\text { No with severe } \\
\text { initial convulsion }\end{array}$} & \multirow[t]{2}{*}{$\begin{array}{l}\text { No of } \\
\text { recurrences }\end{array}$} \\
\hline & & & & & & & & & Febrile & Other & & \\
\hline $\begin{array}{c}\text { Treated p } \\
\text { Boys } \\
\text { Girls }\end{array}$ & $\begin{array}{r}\text { tien } \\
. . \\
. .\end{array}$ & $\begin{array}{l}. \\
\cdots\end{array}$ & $\because$ & .. & $\because$. & $\begin{array}{l}22 \\
27\end{array}$ & $\begin{array}{l}19 \pm 7 \\
20 \pm 6\end{array}$ & $\begin{array}{l}5(23 \%) \\
2(7 \%)\end{array}$ & $\begin{array}{l}1(5 \%) \\
3(11 \%)\end{array}$ & $\begin{array}{l}2 *(9 \%) \\
2(7 \%)\end{array}$ & $\begin{array}{l}2(9 \%) \\
3^{*}(11 \%)\end{array}$ & 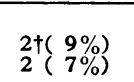 \\
\hline $\begin{array}{l}\text { Controls: } \\
\text { Boys } \\
\text { Girls }\end{array}$ & $\because$ & $\begin{array}{l}\cdots \\
\cdots\end{array}$ & $\because$ & $\because$ & $\because$ & $\begin{array}{l}43 \\
30\end{array}$ & $\begin{array}{l}20 \pm 8 \\
19 \pm 6\end{array}$ & $\begin{aligned} & 11(26 \%) \\
& 7 *(23 \%)\end{aligned}$ & $\begin{array}{l}8^{*}(19 \%) \\
1(3 \%)\end{array}$ & $\begin{array}{l}4(9 \%) \\
2(7 \%)\end{array}$ & $\begin{array}{l}3(7 \%) \\
4(13 \%)\end{array}$ & $\begin{aligned} 10(23 \%) \\
4(13 \%)\end{aligned}$ \\
\hline
\end{tabular}

- One child out of each subgroup indicated had repeat convulsion

† Excludes one boy who had second convulsion just after taking his first dose of phenobarbitone but who subsequently maintained adequate plasma levels. 
An explanation of the contradiction between the conclusion of Faerø et $\mathrm{al}^{7}$ and our own results may lie in the small number of children in the Danish multicentre trial.

Their adequately treated group (mean serum phenobarbitone $69 \mu \mathrm{mol} / \mathrm{l}$ or over) contained only 27 children, and there was only one recurrence. They claimed that this was a highly significant reduction in the recurrence rate, but they compared this group with an entirely different series of 172 untreated children. ${ }^{10}$ If the data of Faerø et al are recalculated simply to compare "adequately" and "inadequately" treated children within their own trial then no significant difference in recurrence rate can be elicited $\left(\chi^{2}=2.55\right.$; $\mathrm{DF}=1$; Yates's correction, $\mathbf{P}=>0 \cdot 1)$. Furthermore, although the serum phenobarbitone was not measured at the time of the single repeat convulsion in their adequately treated group it was $78 \mu \mathrm{mol} / 1$ $(18 \mu \mathrm{g} / \mathrm{ml})$ two weeks before and $69 \mu \mathrm{mol} / \mathrm{l}$ two weeks after the convulsion. Another possible reason for the discrepancy is that the Danish workers used an ultraviolet spectrophotometric method for estimating serum phenobarbitone ${ }^{12}$ while we used gas-liquid chromatography. We have no reason to believe that differences arising from variation in methodology are of more than minor importance. Unlike Faerø et al, we had the advantage of performing all estimations in one laboratory, and our experience in the national antiepileptic drug quality control scheme engenders confidence in the method we used, and that this is a general view is supported by the increasing use of gas-liquid chromatography analyses by participating laboratories.

Earlier uncontrolled trials of phenobarbitone in febrile convulsions ${ }^{8}$ support our own observations. A possible exception is an unpublished trial of phenobarbitone by Livingstone. ${ }^{13} \mathrm{He}$ states that although phenobarbitone did not influence the recurrence rate in those with "simple" convulsions there was a reduction in the number of recurrences in the group of children whose initial febrile convulsion was prolonged or focal. Further critical and well-designed trials may be necessary to clarify this particular point.

Our own trial emphasises the difficulties in maintaining high blood concentrations of phenobarbitone in young children for as short a time as six months. Only 49 of the 88 nominally on treatment maintained it continuously throughout the trial. Even among the 11 with a prolonged severe first seizure, where parental motivation should have been particularly high, only five took the drug from beginning to end. Difficulties in tolerance have been emphasised by others. ${ }^{13-16}$

If phenobarbitone is ineffective in preventing recurrences of convulsions, possible hazards of its use must be considered more seriously. The current treatment of choice in status epilepticus, including febrile status-that is, severe febrile convulsion-is intravenous diazepam. ${ }^{1}{ }^{13} 1417$ There is much evidence, admittedly anecdotal, that phenobarbitone potentiates the respiratory-depressant and hypotensive side effects of injected diazepam. ${ }^{18-21}$ If this is so and if phenobarbitone does not protect against febrile status then the pretreated child may be at a serious disadvantage. ${ }^{1}$

Finally, the incidence of severe convulsions or febrile status should be put in perspective in relation to initial and recurrent episodes. Lennox-Buchthal ${ }^{1}$ pointed out that the proportion of severe convulsions increases with the number of recurrences, but because there are many more children with a first convulsion than with recurrences severe febrile convulsions are absolutely more likely to be initial attacks. Recalculating the graphic data of Lennox-Buchthal (figure 21 ) $^{1}$ shows that in the 218 consecutive children with convulsions in the Gentofte series, twothirds of the severe episodes were the first convulsion in that child's life.

The significance of status epilepticus as the initial manifestation of a tendency to febrile convulsion compares with the general finding in childhood that only a minority have had a previous convulsion before their first episode of status epilepticus. ${ }^{2}$ Since status, febrile or otherwise, is notoriously difficult to control if hours have elapsed since its onset, ${ }^{2}$ a strong case must be made for improving the organisation of emergency medical services to allow early termination of all continuing convulsions.

Even if further trials show that recurrences of febrile convulsions can be prevented by prophylactic medication the importance of the initial seizure makes consideration of emergency care paramount.

We thank Professor J H Hutchison, Dr R A Shanks, and other senior colleagues for allowing us to study patients under their care. We also thank Mr A D McLaren of the department of statistics, Glasgow University, Sister M Hutcheson, health visitor, Miss E C Jamieson of the biochemistry department and her colleagues, and the medical and nursing staff of the accident and emergency department for their help.

Requests for reprints should be addressed to Dr J B P Stephenson, Fraser of Allander Unit, Royal Hospital for Sick Children, Yorkhill, Glasgow G3 8SJ.

\section{References}

${ }^{1}$ Lennox-Buchthal, A M, Electroencephalography and Clinical Neurophysiology, 1973, suppl 32.

2 Aicardi, J, and Chevrie, J J, Epilepsia, 1970, 4, 187.

${ }^{3}$ Gastaut, H, et al, Epilepsia, 1960, 1, 418.

4 Aicardi, J, and Baraton, J A, Developmental Medicine and Child Neurology, $1971,13,660$.

5 Ounsted, C, Fournal of the Royal College of Physicians of London, 1967, $1,273$.

${ }^{6}$ Falconer, M A, Epilepsia, 1971, 12, 13.

7 Faerø, O, et al, Epilepsia, 1972, 13, 279.

${ }^{8}$ Millechap, J G, Febrile Convulsions. Macmillan, New York, 1968.

- MacGee, J, Analytical Chemistry, 1970, 42, 421

10 Franzen, E, et al, Neurology, 1970, 20, 909.

11 Melchior, J C, Buchthal, F, and Lennox-Buchthal, M A, Epilepsia, 1971, 12,55 .

12 Svensmark, O, and Kristen, P, Fournal of Laboratory and Clinical Medicine, 1963, 61, 501 .

${ }^{13}$ Livingstone, S, Comprehensive Management of Epilepsy in Infancy, Childhood and Adolescence. Illinois, C C Thomas, 1972.

14 Chao, D, Paediatrics, ed H L Barnett. New York, Meridith Corporation, 1972.

15 Hutchison, J H, Practical Paediatric Problems. London, Lloyd-Luke, 1975.

${ }_{16}$ Millechap, J G, Postgraduate Medicine, 1965, 37, 22.

17 Gastaut, H, et al, Epilepsia, 1965, 6, 167.

${ }_{18}$ Greenblatt, D J, and Koch-Weser, J, American fournal of Medical Science, 1973, 226, 261.

19 Sawyer, G T, Webster, D D, and Schut, J L, fournal of the American Medical Association, 1968, 203, 111.

20 Prensky, A L, et al, New England fournal of Medicine, 1967, 276, 779.

${ }^{21}$ Bell, D S, British Medical fournal, 1969, 1, 159. 